\title{
Analysis of variation in success rates in conjunctival autografting for primary and recurrent pterygium
}

\author{
S E Ti, S P Chee, K B G Dear, D T H Tan
}

\begin{abstract}
Aims-To evaluate the success rates of conjunctival autografting for primary and recurrent pterygium performed in a tertiary ophthalmic centre.

Methods-The outcome of 139 cases with primary pterygia and 64 cases with recurrent pterygia who underwent excision with conjunctival autografting was retrospectively reviewed. Outcome was evaluated in terms of recurrence of pterygia onto the cornea. The recurrence rates were determined using Weibull survival functions, in a mixture model that included a component allowing for cure. The suitability of this model was verified using Turnbull's non-parametric method for interval censored data (1974). Estimated recurrence free probabilities were based on the fitted Weibull survival curves.
\end{abstract}

Results-Mean follow up was 8.4 months in the primary group, and 9.5 months for the recurrent group. 29 out of 139 cases of primary pterygia recurred $(20.8 \%)$ while 20 out of 64 cases in the recurrent group $(31.2 \%)$ recurred. Recurrence rates varied widely among surgeons, ranging from 5\% to $82 \%$. Recurrence rates were inversely related to previous experience in performing conjunctival grafting. The recurrence free probability was $84 \%$ at 3 months, $73 \%$ at 1 year for primary pterygia, and $80 \%$ at 3 months, $67 \%$ at 1 year for recurrent pterygia. There was no statistical difference in recurrence rates between primary and recurrent groups $(\mathrm{p}=0.80)$.

Singapore National Eye Centre, Singapore

S E Ti

$S$ P Chee

D T H Tan

Department of

Statistics, University of

Newcastle, Australia

K B G Dear

National University of Singapore

D T H Tan

Correspondence to:

Ti Seng-Ei, MD, Singapore

National Eye Centre, 11

Third Hospital Avenue,

Singapore 168751

Accepted for publication

5 November 1999
Conclusion-The success of conjunctival autografting for pterygium in this series varies widely, and may be related to a significant learning curve or differing surgical techniques for this procedure. This may account for the wide variation in reported success of this procedure in the ophthalmic literature.

(Br f Ophthalmol 2000;84:385-389)

Conjunctival autografting for pterygium is perceived to be a safe and effective procedure and is considered to be the procedure of choice by many surgeons if the use of adjunctive antimetabolites or $\beta$ irradiation is not to be considered. However, reported failure rates in the literature vary widely from $2 \%$ to $39 \%$, and in general, do not support this perception of having an overall low recurrence rate.
Conjunctival autografting for pterygium has been performed in Singapore since the late 1980 s with varying degrees of success. We recently reported a low recurrence rate $(2 \%)$ in a single surgeon (DTHT) randomised controlled trial of conjunctival autografting, ${ }^{1}$ but also noted a wide range of success among other surgeons when performing this procedure. We, therefore, determined the range of success rates and the overall success rate of conjunctival autografting in a retrospective audit in our centre, and explored factors that could affect success or failure of this procedure.

\section{Methods}

All patients who underwent conjunctival autografting for pterygium between January 1991 and March 1993 at the Singapore National Eye Centre were identified from operating theatre records. The patients' particulars and details of clinical progress were obtained from hospital notes. The conjunctival autograft was harvested from the superotemporal conjunctiva and secured with $8 / 0$ virgin silk suture. We noted that the postoperative regime was similar between different surgeons and consisted of chloramphenicol $0.1 \%$ and Betnesol (betamethasone $0.1 \%$ ) four times a day for a mean duration of 6 weeks. Patients were reviewed on the first postoperative day, at the end of 1 week, 4- 6 weeks after surgery, and thereafter, 3 to 6 monthly.

In the primary pterygium group, there were 87 eyes $(62.6 \%)$ with 6 months or more of follow up time, and 45 cases (32.4\%) with 12 months or more of follow up. In the recurrent group, 48 eyes $(75 \%)$ were reviewed for 6 months or more after surgery; 38 cases (59.4\%) had 12 months of follow up.

There were 23 ophthalmologists involved in the study and they all had a minimum of 5 years of surgical experience. Twelve surgeons had performed at least eight autograft operations during the study period.

Patients with less than 3 months of follow up were recalled for review. During the review, absence or presence of recurrence was documented. Recurrence was defined as regrowth of pterygium onto the surgical limbus. In those patients in whom the last record showed no recurrence but a recurrence was found on recall review, the whole interval between the last two examinations was used in the analysis. For patients who defaulted this recall review (total of 20 patients), the last recurrence free visit was recorded and the interval used in the survival curve analysis. 


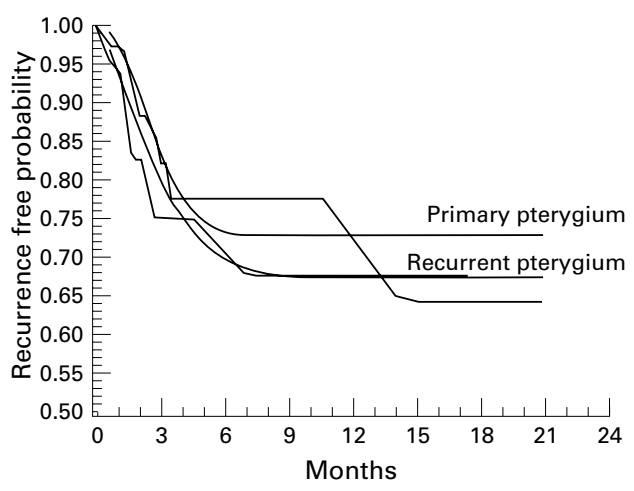

Figure 1 Ordinary lines show recurrence free survival for primary pterygium, bold lines for recurrent pterygium. The irregular lines are estimates derived using Turnbull's method, while the smooth curves are Weibull distributions fitted to the same data, incorporating a proportion of the patients who never have a recurrence.

The surgical outcomes of 139 eyes (133 patients) with primary pterygium and 64 eyes (62 patients) with recurrent pterygium were reviewed. We noted the timing of recurrence in each failed case so as to estimate the minimum period of follow up that would be required to see if surgery had been successful. Risk factors for recurrence were evaluated, with regard to individual surgeon variation, previous surgical experience, and patient demographic factors. Estimated recurrence rates were found using two methods capable of correctly accounting for interval censoring in survival data: a Weibull mixture model, fitted using Microsoft Excel, and the non-parametric method of Turnbull (1974). Interval censored data arise when a patient's failure time may not be observed exactly but is known only to lie between two known times. This is the case with our data; when a patient is seen with recurrence, it is known only that the recurrence had occurred at some point between the current visit and the previous clinical visit.

The Weibull mixture model allowed that some unknown proportion of patients are cured and so never fail, and assumed that the remainder are uncured and will eventually recur at times that follow a Weibull probability distribution. It was necessary to use a parametric model in order to obtain reliable survival curve estimates for individual surgeons, some of whom contributed very few patients. The suitability of the chosen model was investigated by comparison with non-parametric curves fitted to the combined data from all surgeons (Fig 1).

\section{Results}

PATIENT DEMOGRAPHICS AND RECURRENCE RATES

We analysed the surgical outcome of 139 eyes in 133 patients with primary pterygia. There were 103 males and 30 females. The racial distribution approximated Singapore's multiracial Asian population with $82 \%$ Chinese, $12 \%$ Malays, $4 \%$ Indians, and $2 \%$ others. The age range was $27-80$ years with a mean of 44 years. Mean follow up was 8.4 months and ranged from 2 weeks to 26 months (median 6.5 months). Of 139 cases, 29 had less than 3 months of follow up. Of these cases, 19 patients attended recall review.

In the 64 eyes of 62 patients with recurrent pterygium, 48 were males and 14 females. The ages varied from 26 to 73 with a mean of 46 years old. $84 \%$ were Chinese, $12 \%$ Malays, 3\% Indians, and $1 \%$ others (Eurasians). The range of follow up was from 1 to 32 months with an average time of 9.5 months. Of the 17 patients with less than 3 months' follow up, seven patients attended recall review.

Twenty nine out of 139 (20.8\%) primary pterygium cases were found to have recurred during the study period. In the recurrent group, the recurrence rate was 20 out of 64 $(31.2 \%)$. The percentage recurrence free probabilities (likelihood of being without recurrence) based on the fitted Weibull survival curves were calculated at 91,182 , and 365 days (Fig 1).

For the primary group, the percentage survival at 91,182 , and 365 days was $84 \%$, $73 \%$, and $73 \%$ respectively. For the recurrent group, the percentage survival at the same times was $80 \%, 69 \%$, and $67 \%$ respectively. Since these two curves were not significantly different, we calculated the curve for all eyes combined. The percentage survival values were then $83 \%, 72 \%$, and $71 \%$.

\section{VARIATION IN RECURRENCE RATES AMONG} SURGEONS

Of the 23 surgeons within the study, 12 had performed more than eight operations each within the study period; therefore only the results of these 12 surgeons were selected for analysis of recurrence rates (Fig 2).

The individual surgeons' results were tabulated and a wide variation in recurrence rates was documented (Table 1). Surgeon A had the lowest recurrence rate of $5 \%$ (one out of 21 cases) at 6 months' follow up and surgeon $\mathrm{F}$ had the highest recurrence rate of $82 \%$ (nine out of 11 cases). Individual surgeons' performance appeared to correlate well with previous experience (Table 1). Surgeon A was the most experienced, having performed 10 conjunctival autografts before the study period. Surgeon B and $\mathrm{C}$ had previous experience of four and five

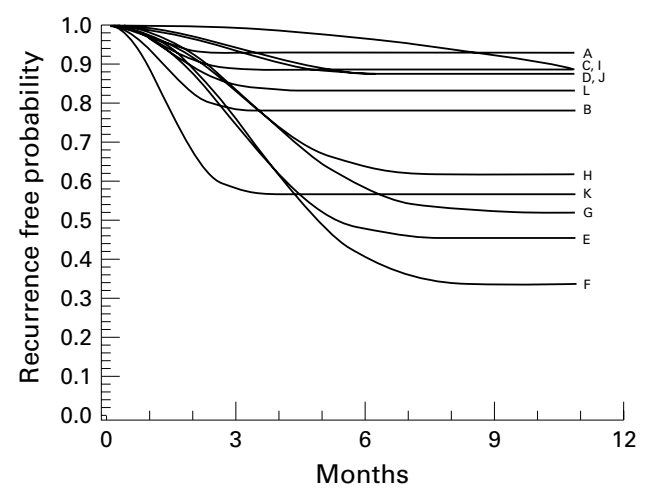

Figure 2 Each curve is a Weibull distribution fitted to the recurrence free times of patients operated on by one surgeon. Only surgeons who contributed at least eight eyes to the data are included. 
Table 1 Individual surgeons' recurrence rates (uncensored, 6 months' follow up) and previous experience

\begin{tabular}{llll}
\hline & $\begin{array}{l}\text { Recurrence rate (\%) for } \\
\text { primary and recurrent } \\
\text { pterygium at 6 months } \\
\text { follow up }\end{array}$ & $\begin{array}{l}\text { Cases which recurred (numbered } \\
\text { according to temporal sequence of } \\
\text { operation) } \\
\text { Case No }\end{array}$ & $\begin{array}{l}\text { Prior experience: } \\
\text { No of cases }\end{array}$ \\
\hline A & $4.8(1$ out of 21$)$ & 1 & 10 \\
C & $10(1$ out of 10$)$ & 8 & 5 \\
B & $13.6(3$ out of 22$)$ & $3,4,5$ & 4 \\
L & $14.2(1$ out of 7$)$ & 7 & 1 \\
D & $20.0(2$ out of 10$)$ & 2,6 & 0 \\
H & $30.7(4$ out of 13$)$ & $1,3,4,12$ & 1 \\
E & $60.0(12$ out of 20$)$ & $1-4,7-10,12,13,16,17$ & 0 \\
G & $60.0(6$ out of 10$)$ & $1,2,4,5,6,9$ & 0 \\
F & $82.0(9$ out of 11$)$ & $1-8,10$ & 0 \\
\hline
\end{tabular}

cases respectively and attained recurrence rates of $13.6 \%$ and $10 \%$ respectively.

In contrast, surgeons $\mathrm{D}, \mathrm{E}, \mathrm{F}, \mathrm{G}$, and $\mathrm{H}$ who had performed none or only one procedure before the study entry obtained high recurrence rates varying from $20 \%$ to $82 \%$.

Being a retrospective audit of hospital records, documentation of certain data was incomplete; it was difficult to take into account other possible confounding factors that could influence recurrence such as exposure to sunlight, timing of surgery, degree of ocular surface inflammation, type of pterygium (fleshy or atrophic), and surgical technique. However, there appeared to be no age bias in patient selection between the various surgeons (Table 2).

INDIVIDUAL SURGEONS' RECURRENCE RATES We looked at the failure cases of the nine surgeons who had performed the most procedures during the study period (Table 1). Although the numbers were small, we noted with interest that it was the earlier cases of some surgeons (A, B, D, E) which developed recurrence.

TIMING OF RECURRENCES

Of the 29 recurrences in the primary pterygium group, $25(86 \%)$ and 27 (93\%) had recurred by 6 and 9 months postsurgery,

Table 2 Number of patients operated on by each surgeon and average patient ages

\begin{tabular}{|c|c|c|c|c|}
\hline \multirow[b]{2}{*}{ Surgeon } & \multicolumn{2}{|c|}{ Primary } & \multicolumn{2}{|c|}{ Recurrent } \\
\hline & $\begin{array}{l}\text { No of } \\
\text { cases }\end{array}$ & $\begin{array}{l}\text { Mean age } \\
\text { (years) }\end{array}$ & $\begin{array}{l}\text { No of } \\
\text { cases }\end{array}$ & $\begin{array}{l}\text { Mean age } \\
\text { (years) }\end{array}$ \\
\hline A & 15 & 51.3 & 13 & 45.4 \\
\hline B & 15 & 53.4 & 7 & 59.7 \\
\hline C & 11 & 44.0 & 1 & 38.0 \\
\hline D & 10 & 46.9 & 2 & 40.5 \\
\hline $\mathrm{E}$ & 25 & 45.9 & 4 & 45.5 \\
\hline $\mathrm{F}$ & 10 & 46.4 & 5 & 48.0 \\
\hline G & 10 & 40.1 & 2 & 44.0 \\
\hline $\mathrm{H}$ & 3 & 59.3 & 13 & 48.6 \\
\hline I & 6 & 50.2 & 4 & 52.5 \\
\hline $\mathrm{J}$ & 9 & 50.7 & 3 & 37.7 \\
\hline $\mathrm{K}$ & 5 & 40.8 & 3 & 37.7 \\
\hline $\mathrm{L}$ & 8 & 43.5 & & \\
\hline M & 4 & 47.3 & & \\
\hline $\mathrm{N}$ & 2 & 63.0 & 2 & 62.0 \\
\hline $\mathrm{O}$ & & & 1 & 43.0 \\
\hline $\mathrm{P}$ & 1 & 37.0 & & \\
\hline Q & & & 1 & 31.0 \\
\hline $\mathrm{R}$ & 1 & 51.0 & 1 & 43.0 \\
\hline S & 1 & 40.0 & & \\
\hline $\mathrm{T}$ & & & 1 & 41.0 \\
\hline $\mathrm{U}$ & 1 & 39.0 & & \\
\hline V & 1 & 31.0 & & \\
\hline W & & & 1 & 36.0 \\
\hline Total & 139 & & 64 & \\
\hline
\end{tabular}

respectively. In the recurrent pterygium group, 17 out of $20(85 \%)$ had recurred by 6 months, with a total of 18 cases (90\%) by 9 months.

\section{OTHER COMPLICATIONS}

No serious complications were documented in this retrospective series. There were five steroid responders who did not progress to glaucoma. Four patients developed a granuloma at the donor conjunctiva site and three patients had conjunctival cysts on the graft. There was one case of scleral thinning in a patient who had had previous pterygium surgery which did not require surgical intervention.

\section{Discussion}

Various surgical techniques have been employed to treat pterygium. The diversity of techniques reflects the ongoing challenge among surgeons to devise the best method for treating pterygium. Many studies have been published with conflicting results. The simplest technique of bare sclera excision alone proved unsatisfactory because of the high recurrence rates $(30-70 \%) .^{2}{ }^{3}$ Adjunctive treatment after bare sclera excision with $\beta$ irradiation reduced recurrence rates to as low as $0.5 \%-16 \%,{ }^{4}$ but was associated with significant complications such as scleral necrosis. The use of mitomycin C was also associated with complications such as secondary glaucoma, corneal oedema, iritis and corneal perforation, endophthalmitis, and cataract. $^{5-7}$

In 1985, Kenyon et $a l^{8}$ published a report describing conjunctival autografting as a promising technique in the treatment of pterygium. They documented a recurrence rate of $5.3 \%$ in the primary pterygium group. Since then, a number of papers on the success of conjunctival grafting have been published, with varying success rates. Lewallen ${ }^{9}$ published the first report of a randomised trial of the conjunctival autografting technique for pterygium removal. In it she documented a lower recurrence rate $(21 \%)$ in grafted cases compared with controls done by the bare sclera technique $(37 \%)$. All her patients were black people who had always lived in the Caribbean. Riordan-Eva et $a l^{10}$ of Moorfields Eye Hospital, London, supported Lewallen's findings when they reported a statistically significant reduction in recurrence rates following conjunctival autografting for pterygium. They quoted a probability of recurrence of $14 \%$ with this procedure at 36 months after surgery. In 1995, Chen et al ${ }^{11}$ reported their results of a randomised trial comparing mitomycin $\mathrm{C}$ and conjunctival autograft after excision of primary pterygium. Their patients were mainly Hispanics living in southern California. The recurrence rates after mitomycin C and conjunctival autograft were $38 \%$ and $39 \%$ respectively after 12.3 and 13.5 months follow up. They concluded that both conjunctival autograft and low dose topical mitomycin C were equally effective as adjunctive treatment after excision of primary pterygium.

We recently reported on recurrence rates in a single surgeon, randomised controlled trial comparing conjunctival autografting with bare sclera excision. ${ }^{1}$ In that study, the 1 year recur- 
rence rate for conjunctival autografting in primary cases was $2 \%$ (one recurrence in 61 eyes), while no recurrences were noted in the recurrent pterygium cases. This was in marked contrast with cases undergoing bare sclera excision in which the recurrence rates for primary and recurrent groups were $61 \%$ and $82 \%$ respectively.

In this study, which had a similar patient source, the 1 year recurrence free probability was only $71 \%$ (likelihood of recurrence by 1 year was $29 \%$ ); the overall mean recurrence rates for conjunctival autografting was $20.8 \%$ and $31.2 \%$ for primary and recurrent groups respectively. The wide range of individual surgeons' recurrence rates ranging from $5 \%$ to $82 \%$ may explain the discrepancy between our two studies, as the surgeon who performed pterygium surgery in the randomised prospective trial was also surgeon A who had the lowest recurrence rate in this series $(5 \%)$.

Several reasons which may explain the wide variation in success of conjunctival autografting in this series include selection bias of case severity among different surgeons, varying surgical techniques, and variation in individual surgical ability, all of which may also explain similar recurrence rate variation in other conjunctival autograft studies.

In our previous prospective randomised trial, we developed a slit lamp biomicroscopy grading for pterygium morphology, and we were able to show that pterygium morphology is a significant factor affecting recurrence rates after bare sclera excision, with fleshy pterygia (grade T3) ${ }^{1}$ having significantly greater chance of recurring, compared with atrophic ones (grade T1). In contrast, we found that patient age was not an independent risk factor for recurrence, as reported by Llewallen; there were simply more aggressive, fleshy pterygia in younger patients. In this retrospective study, data on preoperative pterygium morphology were inadequately recorded in some cases notes, and we accede that it is possible that surgeons with a higher recurrence rate may have chosen to perform surgery on more severe, aggressive pterygia. However, it should be noted that patient age among individual surgeons' cases was not significantly different, suggesting that there was less likelihood of selection bias in this aspect.

The postoperative management between various surgeons was also compared and found to be fairly uniform. Topical chloramphenicol $0.5 \%$ and Betnesol (betamethasone 0.1\%) were prescribed four times a day for a period of 4-8 weeks depending on the degree of graft oedema and redness.

Differences in surgical technique will always occur in studies involving many surgeons who may vary individually in surgical knowledge and expertise in the study procedure, and if these differences affect surgical outcome, variation in success will occur. This applies especially to procedures which are difficult, or have a significant learning curve. Conjunctival autografting is certainly more difficult to perform compared with simple excision, and these new skills and surgical principles, which are different from conventional surgical techniques developed for cataract and other intraocular surgery, need to be learnt. We have found that an important factor for success is the ability to dissect a thin and adequately sized graft to cover the conjunctival defect with minimal inclusion of Tenon's tissue, and without buttonholing. This results in a thin, tension free graft which will not subsequently retract and shrink after surgery. This thin dissection technique differs from conventional conjunctival surgical techniques, such as in glaucoma filtration surgery and squint surgery. In these cases, it is often desirable and much easier to obtain a thick conjunctival dissection with inclusion of Tenon's layer. Other factors which may be important in reducing recurrence include obtaining a large sized graft, adequate clearance of subconjunctival fibrovascular tissue from surrounding conjunctiva and adequate anchorage of graft edges to the episcleral bed with sutures. Of the nine recurrences within the 26 patients recalled for examination, graft shrinkage or excessively small grafts were noted. The presence of a significant learning curve is clearly seen in this study, as surgeons A to $\mathrm{C}$, who had the lowest recurrence rates (mean recurrence rate of $10 \%$ ) had performed a total of 19 conjunctival autografts prior to study inclusion. In contrast, the other six surgeons ( $\mathrm{D}$ to $\mathrm{H})$ attained a mean recurrence rate of $50 \%$, and had collectively only performed two conjunctival autografts before the study. We reviewed the temporal sequence of cases which had recurred during the study period to determine if there was a learning curve effect within each surgeons' experience. Because the numbers were small, we could not demonstrate this factor in every surgeon. However, it was observed that within certain individual surgeon's experience, the later cases tended to be successful (surgeons A, B, D, E). It should also be noted that all the surgeons considered in this study were experienced cataract surgeons with at least 5 years of general ophthalmic surgical experience, and had performed at least eight conjunctival autografts within the study period.

We looked at the timing of recurrences to assess the minimal follow up time required in order to observe most recurrences. In the study by Hirst et $a l,{ }^{12}$ the authors reviewed 161 known pterygium recurrences to determine when these recurrences occurred. Their survival curve analysis showed that there was a $50 \%$ chance of a recurrence within the first 120 days and a $97 \%$ chance there would be a recurrence by 12 months after surgery. In this study, our absolute numbers of recurrences analysed are much fewer; nevertheless, we noted that of the 29 recurrences in the primary pterygium group, $25(86 \%)$ and $27(93 \%)$ had recurred by 6 and 9 months after surgery, respectively. In the recurrent pterygium group, 17 out of 20 ( $85 \%$ ) had recurred by 6 months, with a total of 18 cases ( $90 \%$ ) by 9 months. To date, our local experience concurs with the results of this study-that is, most recurrences following conjunctival autografting tend to occur early, within 6 months of surgery. 
In summary, we have shown that although conjunctival autografting in the best of hands can have an excellent surgical outcome with low recurrence rates, wide intersurgeon variation exists with this procedure. Pterygium excision with conjunctival autografting may be a highly technique dependent procedure and in this study appears to be associated with a significant learning curve.

\section{Conclusion}

Conjunctival autografting for pterygium can be associated with a highly variable outcome. In this series recurrence rates varied $5-82 \%$ among different surgeons (6 months' follow up). Surgeons who had performed more conjunctival autografts for pterygium before the study were found to have a lower recurrence rate, suggesting a learning curve effect. Possible reasons for the variation in success may be case selection and variability in surgical technique.

From the results of this retrospective study, we infer that the variable success of conjunctival autografting may be due, in part, to the variation in surgical technique and skill in performing this procedure. Certainly, an inherent degree of expertise is necessary to perform a superficial dissection of the bulbar conjunctiva and obtain a thin graft which is relatively free of Tenon's layer and therefore does not contract. The size of the graft and suture technique may also be important in preventing recurrence.
This retrospective effectivity study of conjunctival autografting for pterygium serves as a comparative baseline for our prospective clinical study which showed that if performed properly, conjunctival autografting procedure can achieve very low recurrence rates and is undoubtedly superior to bare sclera excision.

1 Tan DHT, Chee SP, Dear K, et al. The effect of morphology on pterygium recurrence in controlled trial comparing conjunctival autografting with bare sclera excision. Arch Ophthalmol 1997;115:1235-40

2 Cameron ME. Pterygium throughout the world. Springfield: Thomas, 1965.

3 Youngson RM. Recurrence of pterygium after excision. $\mathrm{Br} \mathcal{F}$ Ophthalmol 1972;56:120.

4 Mackenzie FD, Hirst LW, Kynaston B, et al. Recurrence rate and complications after beta irradiation for pterygia. Ophthalmology 1991;98:1776-81.

5 Hayasaka S, Noda SN, Yamamoto Y, et al. Postoperative Hayasaka S, Noda SN, Yamamoto Y, et al. Postoperative
instillation of mitomycin C in the treatment of recurrent instillation of mitomycin C in the treatment of
pterygium. Am $\mathcal{f}$ Ophthalmol 1988;106:715-18.

pterygium. Am f Ophthalmol 1988;106:715-18.
6 Dunn JP, Seamone CD, Ostler HB, et al. Development of scleral ulceration and calcification after pterygium excision and mitomycin therapy. Am f Ophthalmol 1991;112:343-4.

7 Rubinfeld RS, Pfister RR, Stein RM, et al. Serious complications of topical mitomycin $\mathrm{C}$ after pterygium surgery. Ophthalmology 1992;99:1647-54.

8 Kenyon KR, Wagoner MD, Hettinger ME. Conjunctival autograft transplantation for advanced and recurrent pterygium. Ophthalmology 1985;92:1461-70.

9 Llewallen S. A randomised trial of conjunctival autografting for pterygium in the tropics. Ophthalmology 1989;96:16124.

10 Riordan-Eva P, Kielhorn I, Ficker LA, et al. Conjunctival autografting in the surgical management of pterygium. Eye 1993;7:634-8

11 Chen P, Ariyasu RG, Kaza V, et al. A randomised trial comparing Mitomycin C and conjunctival autograft after excision of primary pterygium. Am $\mathcal{F}$ Ophthalmol 1995;120: $151-60$

2 Hirst LW, Sebban A, Chant D. Pterygium recurrence time. Ophthalmology 1994;101:755-8. 